\title{
Representações, normas e lugares: contos de contrabando da fronteira gaúcha
}

\section{Adriana Dorfman}

Doutora em Geografia, professora adjunta do Departamento de Geografia e da Pós-Graduação em Geografia da UFRGS. E-mail: adriana.dorfman@ufrgs.br.

Recebido em 04/2012. Aceito para publicação em 12/2012.

Versão online publicada em 01/02/2013 (http://seer.ufrgs.br/paraonde)

\begin{abstract}
Resumo - A partir do estudo do contrabando de pequenos volumes em Santana do Livramento-Rivera, na fronteira Brasil-Uruguai e do exame de obras literárias que o tematizam, o texto propõe que se considere a existência de regimes normativos vigentes em diferentes lugares e escalas geográficas. 0 regime normativo é o conjunto de normas, escritas ou não, válidas para uma comunidade discursiva situada e compartilhando um determinado momento histórico. São demarcações sobre o que é possível, desejável, verossímil, legítimo e justo. A norma é um compromisso entre estruturas (o estado, o mercado, a imprensa, o lugar etc.) e agências (de aduaneiros, de empresários, de comerciantes, de escritores, contrabandistas etc.), definição que pode também ser aplicada às representações sociais. Quando enunciado a partir do estado, o contrabando define-se como o transporte ilegal de mercadorias entre estados, elidindo os tributos por estes estabelecidos, através de um limite de permeabilidade seletiva normatizada por agentes políticos e econômicos hegemônicos. Em condição fronteiriça, contrabandear é representado como um trabalho que implica no desrespeito a algumas leis vigentes nos limites estatais, a partir de um conhecimento do lugar, das práticas possíveis e legítimas nele. Os conteúdos das normas/representações/lugares definem-se também por sua situação, conceito que se refere à relação entre um lugar e seu entorno, enfatizando conexões e acessibilidade. As comunidades situadas - lugares de enunciação específicos - constroem regimes normativos e literatura e estes, ao representar, dialeticamente reconstroem os lugares. 0 estudo da literatura, entendida como representação de uma cultura situada, permite ao geógrafo acessar sentidos locais dos objetos em análise, o que foi exemplificado com a análise de dois contos gaúchos da literatura de fronteira: “Contrabandista”, de Simões Lopes Neto, de 1912, e “Arreglo" de Amilcar Bettega-Barbosa, de 1996.
\end{abstract}

Palavras-chave: Situação. Regime normativo. Contrabando. Lugar de enunciação. Literatura de fronteira

\section{Introdução}

O que eu trago aqui é um debate metodológico, que nasceu de um problema de pesquisa, surgido durante a escrita da minha tese de doutorado sobre os contrabandistas que hoje trabalham na fronteira do Brasil com o Uruguai (DORFMAN, 2009). Eu tentava interpretar a fronteira na escala local descrevendo as práticas dos contrabandistas de pequenos volumes. 0 corpus, o conjunto de documentos que eu analisei, era formado de textos muito diferentes, entre os quais destaco obras ficcionais, os famosos contos de contrabando, e a transcrição de diálogos do trabalho de campo e de entrevistas com pessoas com conhecimento de causa, como contrabandistas, juízes, advogados, aduaneiros, historiadores, professores e geógrafos. Eu também analisei leis, notícias, propagandas, textos acadêmicos e o que mais caísse na minha mão, porque sobre o contrabando paira o sigilo, tanto da parte daqueles que o praticam quanto da dos órgãos de segurança e repressão. Para citar um informante:

aqui nós ainda respeitamos os valores das pessoas, entendesse? Ainda hay um certo pudor, ainda não é escancarado. Tu fica na tua, fica quieto e deixa que eles tussam, entende? Não te mete com nada e pronto, essa é a lei, deixa quieto que eles, vai chegar um momento, eles caem. (entrevista com Robles, Santana do Livramento-Rivera, 25/01/2006).

Então existia esse problema de "esperar eles tussirem", e o sigilo se mostrava como uma moeda forte nos discursos sobre delitos e seguran- 
ça, defendido por contrabandistas e policiais por conta do caráter estratégico de suas operações.

Para aceder aos relatos de contrabando, a essas verdades sigilosas, era preciso contar com a confiança do informante. Como se observa em campo, nessa fronteira o contrabando é bastante legítimo, mas isso não quer dizer que possa ser comentado de qualquer forma e em qualquer situação, menos ainda com aqueles que não fazem parte dessa rede comercial de caráter ilegal. Ou seja, a aceitação social do pesquisador pelos atores territorializados na fronteira é condição para ter acesso à informação sobre o contrabando. 0 sigilo só é rompido quando se é aceito no grupo, o sigilo instala-se no limite entre pertencer ao local ou ser visto como extralocal, criando uma geografia metafórica da informação.

A dificuldade também estava ligada ao caráter informal das práticas estudadas. Estatísticas sobre o contrabando? Em certos casos é possível conseguir balanços de apreensões, mas o contrabando bem-sucedido tende à invisibilidade, não entra nas estatísticas. Além disso, a análise estatística é problemática na fronteira, onde os fenômenos se afastam das normas e justapõem-se bases censitárias geradas a partir de critérios nacionais distintos. Já a etimologia nos mostra a ligação entre o nexo do estado e suas estatísticas.

Agregue-se aos problemas de circunscrição do objeto a coexistência de regimes normativos diferentes em cada lado da fronteira e em cada lugar de enunciação. Todo um esforço teórico foi feito para trabalhar esse corpus diversificado que se oferecia: do contrabando romântico característico dos contos de contrabando às notícias na página policial, passando pela lei do estado e por frases ouvidas em campo. Essa é a história que pretendo contar aqui. Um primeiro problema surge com o estabelecimento da ilegalidade/ legitimidade/ viabilidade do contrabando, que passa pela geografia e pela textualização de cada lugar.

\section{Regimes normativos: leis e normas}

"O contrabando é ilegal, mas não é ilegítimo", "contrabando romântico", contos de contrabando, bons bandidos e outros tropos das explicações positivas sobre contrabando só ganham sentido se pensarmos que surgem de comunidades que experimentam cotidianos que criam e interpretam as normas e leis, estabelecendo seus próprios entendimentos quanto à adoção destas, definindo as regras justas e aplicáveis na comunidade.

0 regime normativo é esse conjunto de normas, escritas ou não, válidas para uma comuni- dade discursiva situada e compartilhando um determinado momento histórico. São definições sobre o que é possível, desejável, verossímil, legítimo e justo. Em sociedades complexas como as nossas, o contrato social é debatido permanentemente, sem ruptura com o estado, a partir de noções locais - mas também de gênero, classe, faixa etária, etnia - sobre justiça, comportamentos e práticas legítimas.

A lei é o regime normativo de legitimidade mais abrangente no território nacional. Cabe resgatar aqui a etimologia da palavra: vem do verbo latino ligare, que significa "aquilo que liga", ou lege$r e$, que significa "aquilo que se lê". Sua redação é um processo lento e controlado, é monopólio do estado (as ditas autoridades competentes). Na prática, comunidades discursivas melhor situadas, em determinados pontos do território, emitem enunciados mais amplamente aceitos, que adquirem força de lei. Por vezes, essas verdades ocultam, reprimem, criminalizam sentidos locais ou desviantes.

Enfim, as leis não são meras manifestações da vontade neutra e abstrata do estado, elas expressam a teia de interesses e encruzilhadas público-privadas que buscam usar o aparato público no desenho da economia, da política, da moral, da cultura no espaço/mercado/lugares reconhecidos como território nacional. Muitas vezes, há uma "privatização" da norma, isto é, esta é usada em proveito de grupos de interesse situados (DORFMAN etal., 2012).

A produção da lei é relevante, mas é importante também problematizar a capacidade de levar à sua observância. Um aparato muito intrincado é construído para administrar o respeito à lei, personificado em polícias e fiscais, peritos e investigadores, juristas e carcereiros etc. A lei estabelece o que é contrabando, mas a decisão de reprimi-lo cabe, em certa medida, aos diferentes agentes que controlam o território estatal - seja nos limites territoriais, em outros pontos de entrada no território nacional como portos ou aeroportos ou nos lugares em que se realiza o consumo.

Dada a impossibilidade de vigiar todas as mercadorias que transitam pelo país, os órgãos de controle estabelecem metas em volume de apreensões e em produtos específicos. A definição dessas metas é, muitas vezes, resultado de um "clamor geral" ou da opinião pública, de um debate que envolve sindicatos de produtores, militantes de direitos sociais e a sociedade em geral, condenando enfaticamente e demandando a repressão a um dado tipo de mercadoria contrabandeada (DORFMAN; REKOWSKY, 2011). 
Obviamente, a opinião pública é formada pela atualização das verdades através dos debates nos meios de comunicação, cujos conteúdos são primariamente definidos por comunidades discursivas ligadas a grandes interesses econômicos ou a órgãos oficiais. Em outras palavras, as fontes mais recorrentemente acessadas pelos jornalistas representam o alcance do poder de certos grupos, $\mathrm{o}$ que está ligado à facilidade e à efetividade da busca de informação por esses profissionais (GRIMBERG; DORFMAN, 2012).

A norma legítima é, portanto, um compromisso entre estruturas (o estado, o mercado, a imprensa, o lugar etc.) e agências (de aduaneiros, de empresários, de comerciantes, de contrabandistas etc.). Localmente, contrabandear é representado como um trabalho que implica no desrespeito a algumas regras vigentes nos limites estatais, a partir de um conhecimento do lugar, das práticas possíveis e legítimas nele. Quando enunciado a partir do estado, o contrabando define-se como o transporte ilegal de mercadorias entre estados, elidindo os tributos por estes estabelecidos, através de um limite de permeabilidade seletiva normatizada por agentes políticos e econômicos hegemônicos.

\section{Lugares de enunciação e cultura situada \\ E o que são lugares de enunciação?} Oswald Ducrot e Tzvetan Todorov conceituam enunciação como "os elementos pertencentes ao código da língua e cujos sentidos, no entanto, variam de uma enunciação para outra; por exemplo, eu, tu, aqui, agora etc." (2001). Por lugar de enunciação entende-se o aqui/agora do autor e de seus interlocutores, nas províncias e redes de poder e representação que o contextualizam.

Os textos, as representações textuais, expressam a cultura espacialmente situada. O lugar da enunciação influi na representação do espaço formulada por cada agente: o agente é situado e a cultura em circulação no lugar condiciona-o, ao regime normativo e às representações que ele cria. Partindo desse ponto, enfatizo a mudança no significado da lei e do contrabando conforme a situação que informa a representação textual formulada por cada agente considerado.

Vou dar uns exemplos de como aparece a lei em textos originados em diferentes lugares de enunciação. Quintana Morales, poeta riverense, escreveu

\footnotetext{
La ley sobre el contrabando no fue hecha en la campaña es como tela de araña no se si muy bien me explico no sujeta al bicho grande pero enreda al bicho chico
}

No Código Penal da República Oriental do Uruguai, escrito com a intenção de regular o mercado nacional, o artigo 245 da lei 13318/1964 reza que

Se considera que existe contrabando en toda entrada o salida, importación, exportación o tránsito de mercaderías o efectos que realizada con la complicidad de empleados o sin ella, en forma clandestina o violenta, o sin la documentación correspondiente, esté destinada a traducirse en una perdida de renta fiscal o en violación de los requisitos esenciales para la importación o exportación de determinados artículos que establezcan leyes y reglamentos especiales, aun no aduaneros

Simões Lopes Neto, escritor e publicista gaúcho do inicio do século $\mathrm{XX}$, escreveu, naquele texto fundador dos "contos de contrabando":

Nesta terra do Rio Grande sempre se contrabandeou, desde em antes da tomada das Missões.[1801]

Naqueles tempos o que se fazia era sem malícia, e mais por divertir e acoquinar as guardas do inimigo: uma partida de guascas montava a cavalo, entrava na Banda Oriental e arrebanhava uma ponta grande de eguariços; abanava o poncho e vinha a meia rédea; apartavase a potrada e largava-se o resto; os de lá faziam conosco a mesma cousa; depois era com gados, que se tocava a trote $\mathrm{e}$ galope, abandonando os assoleados.

Isto se fazia por despique dos espanhóis e eles se pagavam desquitandose do mesmo jeito.

Só se cuidava de negacear as guardas do Cerro Largo, em Santa Tecla, do Haedo... 0 mais, era várzea!

Depois veio a guerra das Missões; o governo começou a dar sesmarias e uns quantíssimos pesados foram-se arranchando por essas campanhas desertas. E cada um tinha que ser um rei pequeno... e agüentar-se com as balas, as lunares e os chifarotes que tinha em casa!...

Foi o tempo do manda-quem-pode!... E foi o tempo que o gaúcho, o seu cavalo e o seu facão, sozinhos, conquistaram e defenderam estes pagos!

Quem governava aqui o continente era um chefe que se chamava o capitão- 
general; ele dava as sesmarias mas não garantia o pelego dos sesmeiros...

Vancê tome tenência e vá vendo como as cousas, por si mesmas, se explicam.

Naquela era, a pólvora era do el-rei nosso senhor e só por sua licença é que algum particular graúdo podia ter em casa um polvarim...

Também só na vila de Porto Alegre é que havia baralhos de jogar, que eram feitos só na fábrica do rei nosso senhor, e havia fiscal, sim senhor, das cartas de jogar, e ninguém podia comprar senão dessas!

Por esses tempos antigos também o tal rei nosso senhor mandou botar pra fora os ourives da vila do Rio Grande e acabar com os lavrantes e prendistas dos outros lugares desta terra, só pra dar flux aos reinóis...

Agora imagine vancê se a gente lá de dentro podia andar com tantas etiquetas e pedindo louvado pra se defender, pra se divertir e pra luxar!... 0 tal rei nosso senhor, não se enxergava, mesmo!...

E logo com quem!... Com a gauchada!... (LOPES NETO, 1998, p. 91)

Três formas de apresentar a lei: uma local, uma nacional, uma regional.

Existe uma quarta forma, a lei da natureza. Quem traz é o Sergio Faraco "era a mesma lei que reinava em sua vida e na vida de seus conhecidos. Todo mundo se ajudava, claro, mas quando alguém morria os outros iam chegando para a partilha dos deixados" (2000, p. 295).

A variação no regime normativo reflete a combinação espaço-tempo-precursores, da mesma forma como se inscrevem nos textos a situação espacial, o contexto histórico de sua produção e leitura e, finalmente, os precursores eleitos pelos emissores. Sejam os textos legais, teóricos ou artísticos, sejam eles cultos ou populares, expressam a cultura espacialmente situada. O lugar da enunciação influi na representação do espaço formulada por cada grupo: o emissor é situado e a cultura em circulação no lugar condiciona-o e às representações que ele cria. Em última análise, a origem espacial do texto está nele expressa, mesmo que não haja nele representação explícita do espaço.

Partindo desse ponto, entende-se a mudança nos conteúdos conforme a situação que informa sua formulação. Situação é um conceito bem explo- rado na Geografia Urbana, e refere-se à relação entre um lugar e seu entorno, enfatizando conexões e acessibilidade. Cabe lembrar o apelo da feminista americana Donna Haraway por saberes situados, em que a objetividade ganhe corporeidade e se reconheça como construção social (1989). Podemos afirmar que, dependendo do lugar em que se produza o texto, e a quem se dirija o argumento, representações muito diferentes da justiça, da fronteira e da condição fronteiriça vão aparecer.

\section{Representações sociais}

No Rio Grande do Sul, o emblema literário mais recorrente é o gaúcho/peão. Da mesma forma, a literatura do Rio Grande do Sul é pródiga em verso e prosa ambientados na região da fronteira. João Pinto da Silva, ao escrever a primeira História Literária do Rio Grande do Sul, ainda em 1922, diagnosticava que em "nossas florações literárias, [...] quando reflexos do ambiente rio-grandense, o tom é um só. De facto, o nosso regionalismo é todo de accentuado cunho fronteiriço, ainda quando a acção de contos e novelas se desenvolve longe da linha divisória" (p.129). Críticos contemporâneos reiteram tal diagnóstico: "a palavra 'fronteira' vem [sendo] [...] objeto de preocupação para todos aqueles que se voltam ao estudo da literatura sul-riograndense - e destacam-se aqui, dentre tantos, os nomes de Guilhermino César, Othelo Rosa, Rubens de Barcellos e Moysés Vellinho (MASINA, 1994, p. 55).

A expressão "literatura de fronteira" tem tido uso corrente em estudos literários no Rio Grande do Sul - vejam-se os trabalhos de Lea Masina (1994, 1995), Nara Rubert (2003) entre outros. A figura 1 apresenta autores e obras publicados até 2009 , sem exaurir a produção dos escritores e certamente omitindo muitos nomes importantes.

Figura 1: Quadro com algumas obras gaúchas da literatura de fronteira

Fonte: DORFMAN, 2009, p. 124.

A literatura de fronteira pode ser reconhecida como um gênero, ao considerarem-se índices como a origem geográfica dos autores, a tematização da fronteira e a interpolação do português, do espanhol e de termos locais, gauchescos, em sua maioria oriundos das línguas indígenas, por vezes assumindo-se como portuñol. Para a constituição do gênero contribuem ainda as referências recíprocas entre os autores, sejam eles contemporâneos ou precursores, e a existência de editoras e de público-leitor, conformando um sistema literário. 0 conceito de sistema literário, no qual a relação entre autores, público e um conjunto de editoras 
formam um sistema, também aplica-se à literatura sul-rio-grandense sem descartar a idéia de literatura da fronteira. Sistema refere-se à organicidade da literatura, "do triângulo "autor-obra-público", em interação dinâmica, e de uma certa continuidade da tradição" (CÂNDIDO, 1981, p.16).

A literatura de fronteira não aparece apenas no Cone Sul. Internacionalmente, é a fronteira entre o México e os Estados Unidos aquela aceita como paradigmática, e não apenas no campo da literatura (GRIMSON, 2000, p.22). Edward Soja, por exemplo, incluiu em Thirdspace, uma análise da cultura e identidade chicana valorizadas como "formas inovativas de interpretação (terceiro)espacial" (t.a) ("innovative new forms of (Third)spatial interpretation", 1996, p. 129). Sonia Torres (2001) organiza sua análise da "literatura, etnografia e geografias de resistência" pelo questionamento da hispanização da cultura norteamericana, da busca de uma voz pelos migrantes latinos que não abandonam suas origens, e das resistências geradas no processo. Uma análise pre-

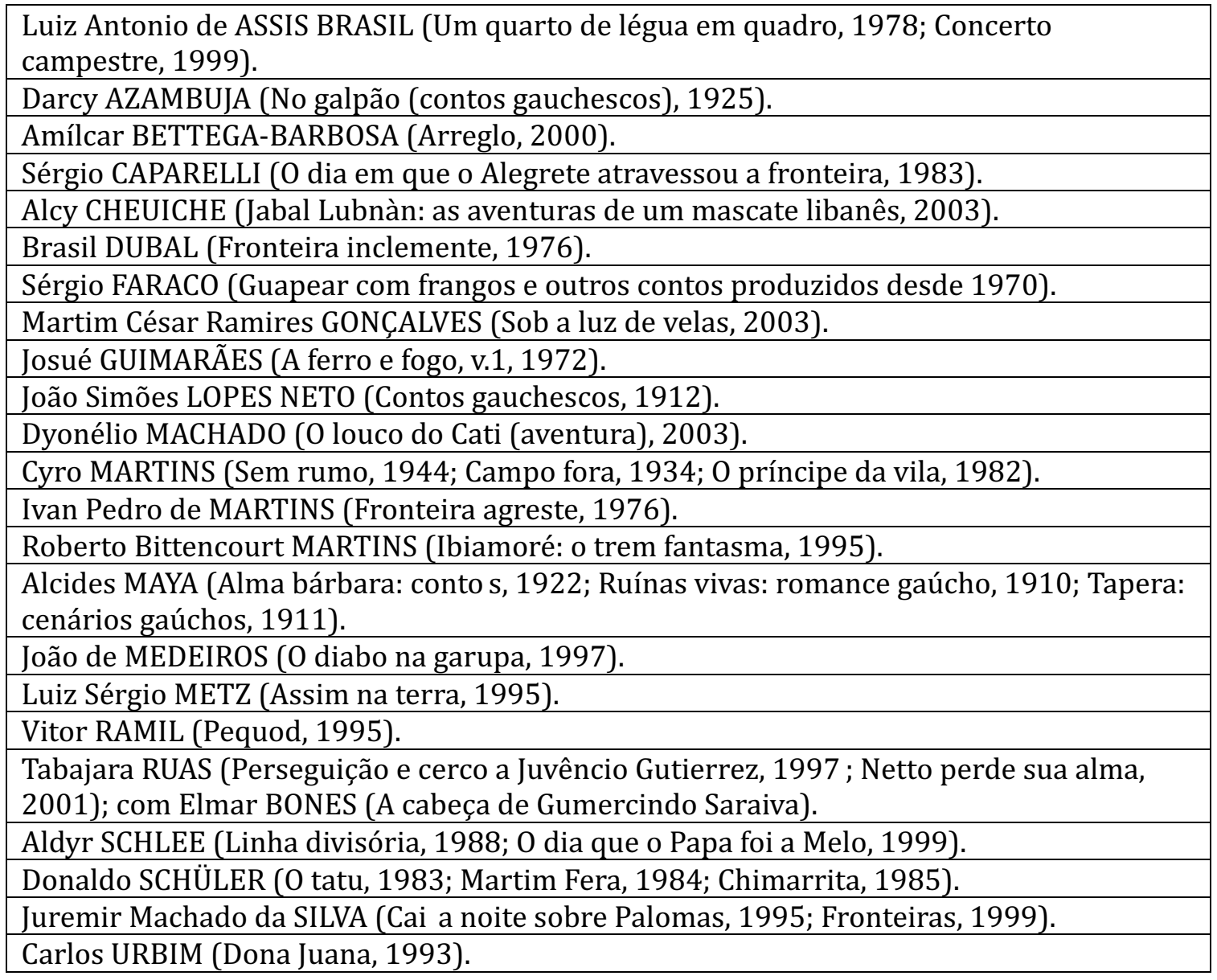

Figura 1. Quadro com algumas obras gaúchas da literatura de fronteira. Fonte: DORFMAN, 2009, p. 124.

liminar da literatura da fronteira México-EUA revela que apenas os latinos e seus descendentes têm tomado a palavra, ou talvez eles sejam mais valorizados por serem considerados pelos teóricos como os portadores da nova representação. A comparação entre a literatura da fronteira gaúcha e a produzida nas borderlands norte-americanas revela ainda que os conflitos são muito mais claramente expostos no segundo caso, refletindo as distintas realidades que as geram (DORFMAN, 2004). Também na França encontrei obras que falam da fron- teira e do contrabando, valorizando a primeira como lugar de memória e o segundo como prática tradicional e marca do lugar (DORFMAN, 2008).

Assim, a literatura do Rio Grande do Sul recebe influxos da fonte revelada pelo uruguaio Bartolomé Hidalgo - que, em 1810, escreveu os "Dialogos Patrióticos" - e valorizada por José Hernández (1834-1886), em “El Gaucho Martín Fierro" (1872) e sua continuação "La vuelta de Martín Fierro" (1874).

Antes de Hernández, José de Alencar escre- 
vera “0 gaúcho” (1870), uma entre várias obras regionalistas através das quais pretendia mapear a diversidade da vida e da paisagem brasileiras. 0 romance de Alencar não foi bem recebido entre os intelectuais do Rio Grande do Sul, por falta de verossimilhança na linguagem e na representação do tipo regional. Como resposta, Apolinário Porto Alegre escreve "O vaqueano” (1872), onde se glorifica a "democracia da estância" (congraçamento entre fazendeiros e peões) (HEIDRICH, 2000, p.136). Note-se que a legitimidade da representação do tipo regional é dada ao argentino Hernández e não ao brasileiro Alencar.

A literatura da fronteira insere-se, portanto, na "comarca literária do Pampa” (RAMA, 1982), compartilhada por sul-brasileiros, uruguaios e argentinos (figura 2). Ao observar o mapa das comarcas literárias, a simultânea pertinência do Rio Grande do Sul ao Brasil e ao Pampa pode ser entendida como uma negação da suposta congruência entre cultura e nacionalismo, onde a fronteira nacional delimitaria língua e práticas culturais. No caso gaúcho, a fronteira é o marcador, o símbolo de uma cultura, de uma especificidade em relação ao Brasil.

A literatura da fronteira produzida no Rio Grande do Sul carrega a ambiguidade de ser a um só tempo não-nacional, mas transnacional, identificada com o regionalismo tradicionalista, conservador e nacionalista. É recorrente a inclusão de glossários nas obras regionalistas editadas nos centros culturais da nação, posicionando os termos ditos regionais nos marginalia da página e restabelecendo a posição periférica, a condição desviante, deste produto cultural. Por outro lado, o conteúdo dos marginalia é compartilhado entre as obras publicadas em outros países do Prata. Há, portanto, uma linguagem da margem, incompreensível no centro, mas comunicando transfronteira, fortemente baseada na oralidade, nas origens híbridas da cultura e dos habitantes desse espaço.

\section{Contos de contrabando}

Os contos de contrabando conformam integram um segmento relevante na literatura de fronteira. Essas representações textuais sublinham a relevância dos aspectos territoriais para aqueles envolvidos nas passagens ilegais da fronteira. Seus enredos tematizam as práticas dos "bagayeros", suas relações sociais e as formas de habitar o lugar.

Ainda que o valor estético ou artístico de alguns contos de contrabando possa ser questionado, é evidente a rentabilidade da análise dessas representações situadas - sobre as trocas que a fronteira permite, sobre o confronto de identidades, sobre o regime normativo incidente sobre as práticas - sobre a condição fronteiriça.

A fim de estabelecer hipóteses sobre práticas, normas e condição fronteiriça relevantes para contrabandistas de pequena monta em Santana do Livramento-Rivera examino aqui dois contos de autores nascidos na fronteira Brasil-Uruguai, escritos no limite entre texto culto e narrativa nativa. Esses contos foram pinçados devido a referências mutuas, intertextualidades mais ou menos explícitas, reconhecimento por parte da crítica e circulação entre leitores.

O uso de uma linguagem local é um recurso compartilhado pelos textos. Ligia Chiappini (1999, p. 21) cita Dino Preti (1977, p. 42-3, 47) para enumerar estratégias a que um dos autores estudados, Simões Lopes Neto, recorre em seu esforço para transcrever a oralidade:

a redundância; a freqüência das expressões de situação (aqui, ali, agora...); o truncamento básico; o ritmo e sonoridade típicos da fala; o papel da pontuação ressaltando a afetividade; a imagem do interlocutor; as interjeições e chamamentos, pelo vocativo; as questões, supostamente dirigidas ao interlocutor e, por meio deste, ao leitor-ouvinte; as comparações dentro do horizonte de Blau; os castelhanismos.

0 conto mais antigo e conhecido aqui analisado é Contrabandista. É provável que João Simões Lopes Neto seja o pai dos contos de contrabando no Rio Grande do Sul. 0 título refere-se a Jango Jorge, descrito como um homem de muito valor e habilidade, fortemente arraigado no pago, que se notabilizava pelo conhecimento da região, que "nunca errou vau, nunca perdeu atalho, nunca desandou cruzada", localizando-se pelo faro, pelo ouvido e até pelo gosto característico a cada lugar (LOPES NETO, 1998, p. 91).

A história se passa em meados do século XIX, mas remete também ao tempo passado: já velho e afamilhado, Jango Jorge ia casar sua filha. Saiu na véspera da boda para buscar o enxoval do outro lado do rio - e da fronteira. Todos os preparativos estavam concluídos, mas a noiva não podia aparecer na festa enquanto o pai não chegasse com seus atavios. Depois de tensa espera, um movimento no terreiro anuncia Jango Jorge: deixando sua experiência de lado, insistira em enfrentar a guarda de fronteira e fora morto.

Além da rica informação factual deliberadamente incluída nessa obra, e em parte transcrita 


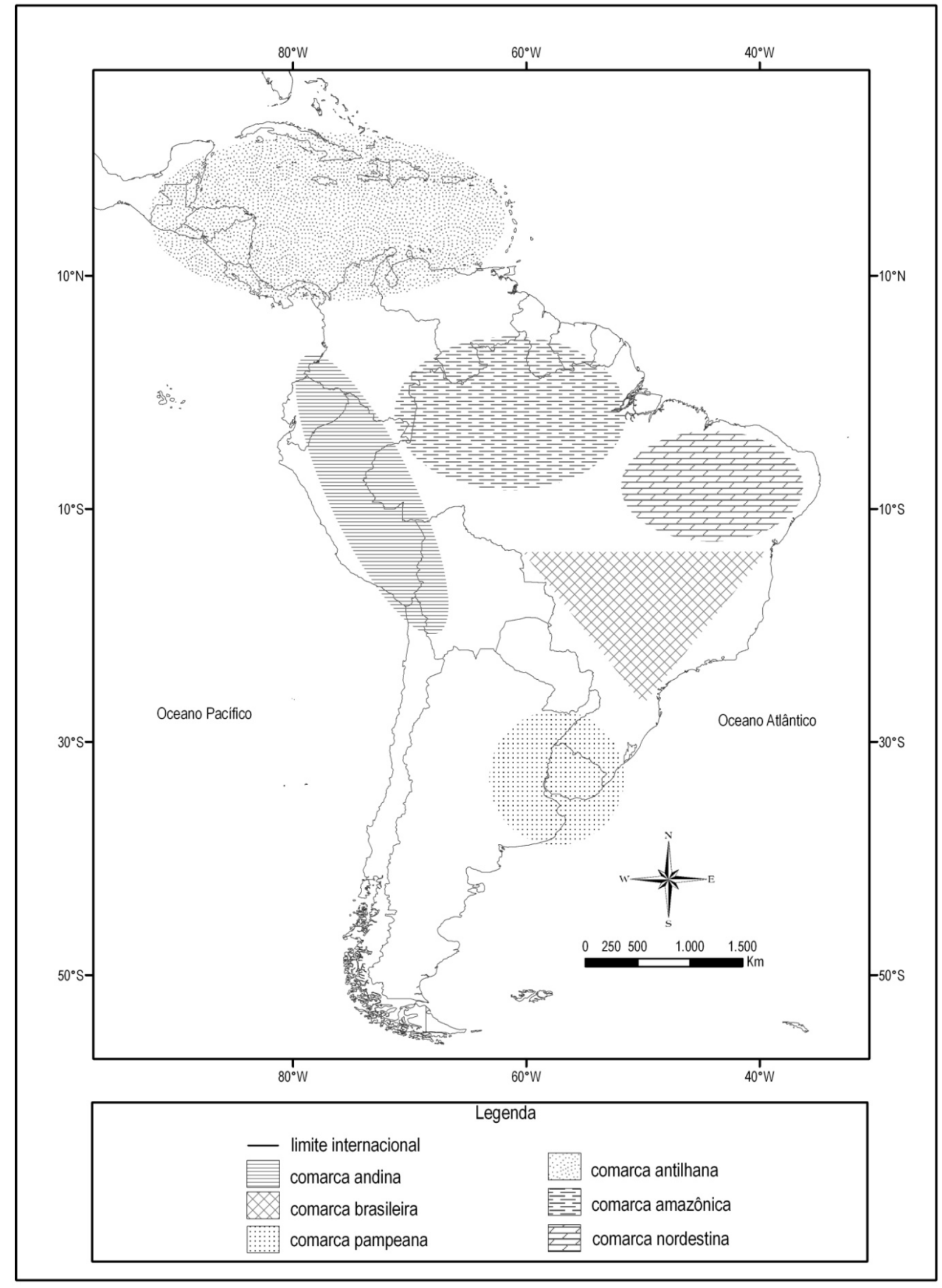

FIGURA 2: América Latina: mapa das comarcas literárias. Fonte: DORFMAN, 2009, p. 127 
acima, o desejo de registro é tão explícito que podese afirmar tratar-se de um conto a serviço do documento - aprende-se que o contrabando é uma prática tradicional na região, e que desde sua origem, anterior a 1800, organizava-se em bandos ou "malocas", atuando nos banhados do rio Ibirocaí, com qualquer tempo e a qualquer hora do dia (LOPES NETO, 1998, p. 91). Segundo o autor, o contrabando teria nascido porque os estancieiros iam ou mandavam buscar artigos necessários ou supérfluos para seu abastecimento do outro lado da fronteira ainda mal-definida.

É evidente sua intenção em registrar a gênese e a organização do contrabando, apresentandoo como estratégia de sobrevivência da população diante de uma dinâmica histórica desterritorializante, e não como crime ou contravenção. 0 personagem-título surge com muita humanidade, como um pai dedicado, generoso e conhecedor da terra, e a ele opõem-se os "ordinários" guardas da fronteira. 0 contrabando que leva à morte de Jango Jorge não são armas nem drogas, mas um enxoval, a proteção e a delicadeza legada por um pai a sua filha. 0 casamento vira funeral, o dia vira noite, por causa do combate entre o capitão-contrabandista-pai da noiva, próximo e familiar, e os ordinários que defendem a lei do estado. É preciso lutar para reaver o corpo do contrabandista.

0 contexto histórico é reforçado pelo escritor-testemunha, ciente de seu papel social (o que é corroborado por sua opção por um personagem de extração social baixa, tal qual os bagayeros) escolhendo registrar a dor desencadeada pela desarticulação de um certo mundo rural. A sobreposição dos papéis de autor/testemunha permite o uso desse material na pesquisa geográfica: os textos ecoam um coletivo humano territorializado, sua oralidade, seu regime normativo. Eles representam uma vida de transgressões à norma nacional em condição fronteiriça.

0 autor contemporâneo Amilcar BettegaBarbosa (1964- ) escreveu "Arreglo" - que pode significar arranjo, suborno, reparação ou rendição - em 1996 (BETTEGA-BARBOSA, 2000). Essa história não louva o gaúcho ou sua região, como no começo do século XX. Ela mostra um lugar marginal e violento, "esvaziado de perspectivas", onde o contrabando é uma "alternativa à falta de alternativas" (entrevista, Paris, 23 de março de 2007). 0 conto se passa numa fronteira marginalizada pela economia e pela geopolítica, entre quartos de cabaré e um parador na Federal, em Rosário do Sul. O posto de serviços da rodovia Federal, que poderia ser descrito como um não-lugar - não fosse o uso da expressão local - sublinha a presença do nacional e aponta para a articulação supranacional através da estrada para a Argentina. A ação se desenrola na cidade, o entorno rural é descrito como miserável, o rio é só um cenário. Não há menção a cavalos, sequer como ornamentos da masculinidade, mostrando ter-se terminado o tempo dos cavaleiros em tropeadas campo afora. Outras escalas e redes organizam o território.

Arreglo inicia com o assassinato do contrabandista Vico por Mendes. Como numa tragédia grega, o narrador é levado, pela honra que oprime por inexeqüivel, a vingar essa morte, apesar de querer mudar de vida para casar. Vico, o contrabandista morto por Mendes ainda antes do início da narrativa, era "chibeiro pequeno, talvez dos últimos numa época em que o chibo perdia a força e o rio já não passava de uma paisagem d'água irmanando a miséria". Aparentemente o assassinato tivera motivação passional, uma disputa pela prostituta adolescente Sarita, mas na verdade outra era mulher em questão. A irmã mais moça de Mendes havia sido estuprada por Vico e engravidara. Miséria e a violência atingem a todos. 0 desfecho é bárbaro: depois de surrar Mendes brutalmente, o narrador solta um cachorro esfomeado e feroz que termina de matá-lo. O corpo é desonrado definitivamente pelos cachorros.

Um ódio ao gaúcho mítico, que poderia ser uma projeção do idealizado Jango Jorge, se manifesta no conto, exemplificando o contínuo espelhamento e distorção entre a literatura e a vida: os gaúchos saem da vida para a idealização na literatura (no "Contrabandista"), voltam à literatura expressando a impossibilidade de cumprir com tal destino numa vida transformada, frustrada e empobrecida (em "Arreglo"). A comparação entre as duas histórias mostra uma transformação no lugar, em seus habitantes e em suas representações.

A importância estratégica e os tempos heróicos pertencem ao passado da fronteira, tanto no lugar quanto nas histórias que ele inspira. A legitimação do contrabando no lugar se mantém, associado à esperteza, rebeldia e coragem. 0 contrabandista é portador de verdades locais, associadas à territorialidade fronteiriça, baseadas nos regimes normativos que permitem ao fronteiriço negociar as leis estatais.

Ao fim desse diálogo entre representações textuais, revela-se um continuum entre os contrabandistas de ficção, como se fossem refigurações de um mesmo personagem, adaptando-se às transformações do espaço que habitam, dialogando com a tradição da literatura e dos costumes. Sendo a fronteira um objeto geográfico, e havendo uma estreita relação entre os objetos geográficos e a 
produção de cultura, sabendo que a sociedade se territorializa gerando representações textuais e que essas mesmas representações textuais entram na construção cultural e política dos lugares pode-se afirmar que a fronteira gera uma cultura específica. 0 contrabando é, nesse sentido, uma prática cultural conectada com a condição fronteiriça. Há uma sobreposição entre a prática do contrabando e a cultura da fronteira, cujos índices mais reconhecidos são o portuñol, as famílias mistas, a política transfronteiriça, a música e a literatura de fronteira.

As obras locais sobre contrabando apelam para o folclore ou para a "contracultura", fazem o elogio do passado ou da margem. Um folclore que imagina um território originalmente isento de fronteiras, criadas por imposição de poderes maiores ou externos, que mutilaram o território original sem, no entanto, extinguir, nos seus habitantes, o nexo pregresso. A contracultura, a poesia da margem, atribui à região fronteiriça valores como liberdade, autenticidade, criatividade, alinhando-se aos pobres para exaltar seu inconformismo. Toda essa legitimação se estende a contrabando de maior monta, com outros propósitos, às vezes bem menos nobres.

Por outro lado, a cumplicidade moral leva a uma coesão interna: os níveis de envolvimento com a atividade variam, há os que são cúmplices apenas no sentido de partilharem o sigilo e não condenarem a prática. Esse grupo - a sociedade local - não é uma classe social, nem um grupo profissional, nem uma facção política. Os bandos e seus cúmplices abrangem uma grande parte ou a totalidade da população do lugar. Deve-se acrescentar que o contrabando dá coesão e identidade, mas não de uma forma pacífica, acomodada. Há embates, disputas, mortes, beneficiados e prejudicados. Conflitos, enfim. Podemos concluir que há um saber e uma identidade nessa sociedade, nesse lugar, mas não há justiça.

Cabe pontuar que valorizar o contrabando como prática local é problemático em outras escalas: reivindicar o delito conforma uma sociedade fora da norma nacional, dando chance à estigmatização. Corre-se o risco de representar a fronteira como ameaça à segurança pública, reforçando uma geografia moral em que diferentes lugares do espaço abrigam e estimulam valores como impureza, ameaça e delinquência. A estigmatização da fronteira, pressupondo uma influência moral sobre seus habitantes, é presente em diferentes representações, seja pela mudança legal e territorial, pela situação periférica ou pelo contato/contágio com o estrangeiro/outro (DORFMAN, 2009; PARK, 1973, p.66).

\section{Concluindo}

A literatura de fronteira e, especificamente, os contos de contrabando revelam lances e nuances do comércio ilícito internacional e da sociedade em que é praticado. A série de narrativas aqui encadeadas mostra que o tema mantém-se em movimento, integrando-se na corrente de representações textuais em que circulam leitores e autores, contrabandistas fictícios e reais.

Como estratégia de aproximação aos sentidos locais do contrabando, a literatura nos forneceu subsídios, que servem como orientação para o trabalho de campo, no levantamento das práticas dos fronteiriços. Alinhando tradição, costumes e práticas, podemos nos aproximar dos hábitos ou costumes que se fazem no espaço social, que trazem em si a ciência do lugar, dos pais e dos precursores, ao mesmo tempo em que necessariamente se territorializam no presente.

De forma resumida, vou colocar algumas conclusões desse trabalho, dessa tentativa de organizar os textos segundo as representações sociais e a situação geográfica:

1. Existem diferentes modos para representar o espaço e as práticas que o ativam socialmente. A representação textual assume diferentes gêneros (uma matéria, uma lógica, um suporte) para verbalizar o espaço, com diferentes propósitos: descrição científica, obra ficcional, texto legal e jornalístico, entrevistas, conversas, causos, anedotas, canções...

2. Todo mundo fala, as palavras e seus usos são de domínio geral, em mutação e atualização permanente, mas cada gênero tem características destacadas, leis internas. 0 texto científico prima pelo diálogo com os precursores; a escrita geográfica também é cartográfica. A representação oral recorre a gestos e entonações, perdidos na passagem para o registro escrito. Cabe examinar o conteúdo local das palavras.

Os elementos de uma geografia da imaginação cultural são

- o lugar do emissor, o ponto de partida da representação, o lugar de enunciação, o aqui e agora subjacente a cada texto.

- o lugar de recepção, a quem se dirige o texto, enfim, a situação do texto, sua vinculação com diferentes entidades geográficas, sua posição periférica ou central a outras representações sociais. Esse tipo de análise sublinha ainda a suíte escalar em que circula o texto, por exemplo, o contrabando, e os conflitos gerados na relação entre representações oriundas no lugar, na região e no Estado. 
Há, evidentemente, um forte teor político nessa formulação. As várias representações textuais da fronteira e do contrabando alinham-se em posições geograficamente coerentes com a situação geográfica e social de quem as produz.

Para fazer uma geografia da imaginação cultural precisamos

(a) reconhecer a natureza desigual de cada um desses gêneros textuais,

(b) aproximá-los, construindo comensurabilidades entre textos de origem, suporte e propósitos distintos,

(c) situá-los no lugar (com suas práticas) e na tradição (que não abordamos aqui),

(d) gerando novas representações textuais, como o texto que aqui se encerra.

\section{Referências}

BETTEGA-BARBOSA, Amílcar. Arreglo. In: EQUIPE DA UNIDADE EDITORIAL (Org.). Contos sem fronteiras. Edição bilíngüe em português e espanhol. Porto Alegre: UE/ Sec. Mun. da Cultura, [1996] 2000,378 p. p.55-62

CÂNDIDO, Antônio. Prefácio da 2ª edição e Introdução. In: __. Formação da literatura brasileira (momentos decisivos). São Paulo: EdUSP/ Ed. Itatiaia Ltda, [1950] 1981.

CHIAPPINI, Ligia. No entretanto dos tempos: literatura e história em João Simões Lopes Neto. São Paulo: Martins Fontes, 1988.416 p.

DORFMAN, Adriana. "O espaço age sobre o estilo": comparando fronteiras através da literatura de gaúchos, chicanos e europeus. Anais do VI Congresso Brasileiro de Geógrafos. Goiânia: AGB, 2004.12 p.

DORFMAN, Adriana. "Pequenas pontes submersas": interpretações geográficas e antropológicas de literaturas de contrabando. Bol. Mus. Para. Emílio Goeldi. Ciências Humanas, Belém, v. 3, n. 1, p. 93 114, jan.-abr. 2008.

DORFMAN, Adriana. Contrabandistas na fronteira gaúcha: escalas geográficas e representações textuais. Tese de doutorado, Florianópolis, 2009. Disponível em http://www.tede.ufsc.br/teses /PGCN0367-T.pdf.

DORFMAN, Adriana; FRANÇA, Arthur Borba Colen; DURAN, Roberta Corseuil; SOARES, Guilherme de
Oliveira. "Contrabando e mercado legal de agrotóxicos: articulações a partir da fronteira BrasilUruguai". Anais do IV Seminario da America Platina. Buenos Aires, 2012.

DORFMAN, Adriana; REKOWSKY, Carmen J. Geografia do contrabando de agrotóxico na fronteira gaúcha. Revista Geográfica da América Central da Escola de Ciências Geográfica, v. 1, p.xx, 2011.

DUCROT, Oswald; TODOROV, Tzvetan. Dicionário enciclopédico das ciências da linguagem. São Paulo: Perspectiva, [1972] 2001.339 p.

FARACO, Sérgio. Guapear com frangos. In: EQUIPE DA UNIDADE EDITORIAL (Org.). Contos sem fronteiras. Edição bilíngüe em português e espanhol. Porto Alegre: UE/ Sec. Mun. da Cultura, [1986] 2000, 378 p. p.289-295.

GRIMBERG, Daniela Seixas; DORFMAN, Adriana. "Uma geografia da informação das apreensões de agrotóxicos na região Sul do Brasil". Anais do Encontro Internacional Fronteiras e Identidade. Pelotas, 2012.

GRIMSON, Alejandro. Introducción ¿Fronteras políticas versus fronteras culturales? In:

(comp.) Fronteras, naciones e identidades: la periferia como centro. Buenos Aires: Ciccus, La Crujía, 2000.348 p.p 9-40.

HARAWAY, Donna. Situated knowledges: the science question in feminism and the privilege of partial perspective. Feminist Studies, Vol. 14, n. 3 (outono, 1988), pp. 575-599 Disponível em http:// www.jstor.org/stable/3178066. Acesso em 07 ago 2012.

HEIDRICH, Álvaro Luiz. Além do latifúndio: geografia do interesse econômico gaúcho. Porto Alegre: Ed. da Universidade / UFRGS, 2000, 212 p.

MASINA, Lea. O contrabando na confluência das culturas. In: CASTÉLLO, I. et al (orgs.). Práticas de integração nas fronteiras: temas para o Mercosul. 1995, p. 165-175.

MASINA, Lea. Percursos de leitura. Porto Alegre: Instituto Estadual do Livro; Movimento, 1994. $159 \mathrm{p}$.

MOSCOVICI, Serge. Representações sociais: investigações em psicologia social. Rio de Janeiro: Vozes, 2003. 
PARK, R. E. "A cidade: sugestões para a investigação do comportamento social no meio urbano". In: VELHO, O. (org.) 0 fenômeno urbano. Rio de Janeiro: Zahar, 1973.

RAMA, Ángel. Transculturación narrativa en America Latina. México: Siglo XXI, 1982.

RUBERT, Nara Marley Aléssio. 0 regionalismo de Sérgio Faraco. Uma visão universalista da literatura de fronteira. Dissertação de Pós-Graduação em Letras. Porto Alegre: UFRGS, 2003,135 p.
SILVA, João Pinto da. História literária do Rio Grande do Sul. $2^{\text {a }}$ ed. P. Alegre: Livraria do Globo, $1930.280 \mathrm{p}$.

SOJA, Edward W. Thirdspace. Journeys to Los Angeles and other real-and-imagined places. Cambridge, Massachusetts: Blackwell, 1996, 334 p.

TORRES, Sonia. Nosotros in USA: literatura, etnografia e geografias de resistência. Rio de Janeiro: Jorge Zahar, 2001, 186 p. 


\title{
Norm, representation and places: smuggling short stories on gaucho border
}

\begin{abstract}
Based on the study of small-volume smuggling in the city of Santana do Livramento-Rivera at the border between Brazil-Uruguay and on the analysis of its literary production, this text considers the existence of normative regimes in different places and geographical scales. The normative regime is the set of rules, written or not, valid for a discursive community situated at a specific time and place. It expresses what is possible, desirable, legitimate, credible and fair. The norm is a compromise between structures (the state, the market, the press, the place etc.) and agencies (customs guards, businessmen, merchants, smugglers, writers etc.). This definition can also be applied to social representations. When represented by the state, smuggling is defined as the illegal transport of goods across state limits, evading taxes through a permeable limit normed by hegemonic political and economic agents. In the border condition smuggling is represented as work - that implies disrespect to some laws in force in state limits - made possible by the knowledge of the place and of the practices that are conceivable and legitimate in it. The contents of the norms/representations/places respect their situation, that is, the relation between a place and its surroundings, emphasizing connections and accessibility. Communities are situated - they are specific places of enunciation - and express normative regimes and literature which represent and dialectically rebuild the places. The study of literature, understood as a representation of situated culture, allows geographers to accede to local contents of the objects under analysis. This was exemplified by the study of two border literature short stories: "Contrabandista" (Eng. smuggler) written in 1912 by Simões Lopes Neto, and "Arreglo" (Eng. arrangement, bribery, reparation or surrender) by Amílcar Bettega-Barbosa, published in 1996.
\end{abstract}

Keywords: Situation. Normative Regime. Smuggling. Place of enunciation. Border literature

\section{Representaciones, normas y lugares: cuentos de contrabando de la frontera gaucha}

Resumen - Partiendo del estudio del bagayo, contrabando de pequeño volumen, en Santana do Livramento-Rivera, frontera entre Brasil y Uruguay, y del examen de obras literarias que la tematizan, el texto propone considerar la existencia de regímenes normativos en diferentes lugares y escalas geográficas. El régimen normativo es el conjunto de reglas, escritas o no, válido para una comunidad discursiva en un momento histórico determinado. Son definiciones sobre lo que es posible, deseable, legítimo, verosímil y razonable. La norma es un compromiso entre estructuras (el estado, el mercado, la prensa etc.) y agencias (aduaneros, comerciantes, empresarios, escritores, contrabandistas etc.), definición que puede aplicarse también a las representaciones sociales. Cuando enunciado desde el estado, el contrabando se define como el transporte ilegal de bienes entre estados, elidiendo impuestos por estos establecidos, a través de un límite de permeabilidad selectiva normatizado por los agentes políticos y económicos hegemónicos. En la condición fronteriza, se representa el contrabando como un trabajo normal, que no respeta a ciertas leyes vigentes en los límites del Estado, lo que exige un conocimiento del lugar, de las prácticas posibles y legítimas en él. El contenido de las normas/representaciones/lugares se define por su situación, concepto que se refiere a la relación entre un lugar y sus alrededores, subrayando conexiones y accesibilidad. Las comunidades situadas - lugares de enunciación específicos construyen regímenes normativos y literatura y estos, al representar, dialécticamente reconstruyen los lugares. El estudio de la literatura, entendida como representación de una cultura situada, permite al geógrafo el acceso a los sentidos locales de los objetos de análisis, lo que se ejemplifica con la discusión de dos cuentos de la literatura de la frontera gaucha: "Contrabandista", de Simões Lopes Neto, del 1912, y "Arreglo", de Amílcar Bettega-Barbosa, del 1996.

Palabras-clave: Situación. Régimen Normativo. Contrabando. Lugar de enunciación. Literatura de Frontera. 